\title{
Pendekatan Health Belief Model (HBM) untuk Menganalisis Kepatuhan Pasien Diabetes Melitus Tipe 2 dalam Menggunakan Insulin
}

\section{Adopting Health Belief Model Theory to Analyze the Compliance of Type 2 Diabetes Mellitus Patient When Using Insulin Injection}

\author{
Yunti Fitriani ${ }^{1,2}$, Liza Pristianty ${ }^{1 *}$, Andi Hermansyah ${ }^{1}$ \\ ${ }^{1}$ Fakultas Farmasi, Universitas Airlangga, Jl. Mulyorejo, Surabaya, Indonesia \\ ${ }^{2}$ Dinas Kesehatan Provinsi Jawa Timur, Jl. Ahmad Yani, Surabaya, Indonesia \\ *Corresponding author email: liza-p@ff.unair.ac.id
}

Received 9-9-2019 Accepted 23-10-2019 Available online 30-12-2019

\begin{abstract}
ABSTRAK
Ketidakpatuhan penggunaan insulin pada pasien Diabetes Melitus (DM) dapat mengakibatkan kegagalan terapi. Pada pasien DM tipe 2, tingkat kegagalan berpotensi meningkat karena dipengaruhi oleh perilaku pasien yang awam dalam menggunakan insulin. Penelitian ini bertujuan untuk menganalisis kepatuhan pasien DM tipe 2 dalam menggunakan insulin yang benar dengan pendekatan teori Health Belief Model (HBM). Metode yang digunakan adalah survei kepada pasien DM Rawat Jalan di suatu Rumah Sakit (RS) di Surabaya dengan responden dipilih menggunakan teknik purposive sampling. Data dianalisis dengan uji regresi linier berganda untuk mengukur pengaruh lima komponen HBM yaitu (1) perceived susceptibility, (2) perceived severity, (3) perceived benefit, (4) perceived self-efficacy, dan (5) perceived barrier terhadap kepatuhan pasien dalam menggunakan insulin yang benar. Hasil penelitian menunjukkan lima komponen memiliki pengaruh yang simultan terhadap kepatuhan penggunaan insulin. Empat komponen awal (1-4) memiliki pengaruh positif (semakin tinggi semakin patuh) sedangkan komponen 5 memiliki pengaruh negatif (semakin rendah semakin patuh). Perlu adanya upaya terstruktur dan berkelanjutan dari pihak RS untuk meningkatkan komponen 1-4 dan menurunkan komponen 5.
\end{abstract}

Kata kunci: diabetes melitus, health belief model, insulin, kepatuhan.

\section{ABSTRACT}

Non-compliance with the use of insulin in patients with Diabetes Mellitus (DM) can lead to therapeutic failure. The failure rate may increase in patients with type 2 DM as they are not familiar with the use of insulin. This study aimed to analyze the compliance of patients with type 2 DM in using insulin using the Health Belief Model (HBM) theory approach. A survey was conducted in a hospital involving outpatients as the 
respondents. The respondents were selected using a purposive sampling technique. Data were analyzed with multiple linear regression tests measuring the effect of five HBM components, namely (1) perceived susceptibility, (2) perceived severity, (3) perceived benefit, (4) perceived self-efficacy dan (5) perceived barrier in using insulin properly. The results showed that five components had a simultaneous effect on patient compliance. The first four components had a positive effect (the higher the more compliant), while component 5 had a negative influence (the lower the more compliant). Hence, the hospital is recommended to provide initiatives to increase component 1-4 and decrease component 5.

Key words: diabetes mellitus, health belief model, insulin, compliance.

\section{Pendahuluan}

Diabetes melitus adalah suatu penyakit gangguan metabolik dengan karakteristik hiperglikemia yang terjadi karena kelainan sekresi insulin, kerja insulin, atau keduanya (Perkeni, 2015). Prevalensi pasien DM semakin meningkat dari tahun ke tahun dengan Indonesia menempati urutan keempat di dunia sebagai jumlah penderita diabetes melitus terbanyak (Aini et al., 2011). Hasil Riset Kesehatan Dasar (Riskesdas) tahun 2018 menyatakan bahwa prevalensi DM penduduk usia $\geq 15$ tahun di Indonesia adalah sebesar $2 \%$ (Riskesdas, 2018).

Saat ini insulin merupakan terapi yang paling efektif untuk penderita DM namun pasien cenderung melakukan penolakan terhadap pemberian insulin melalui injeksi. Beberapa pasien menolak melakukan injeksi insulin karena takut dengan jarum suntik, takut terhadap cara penyuntikan, takut mencelakai diri sendiri, perasaan cemas (Rubin et al., 2009) dan ketidakpuasan terhadap hasil terapi dengan insulin (Alfian, 2016). Penderita DM juga menyatakan ketakutan saat melakukan injeksi insulin secara mandiri sehingga memaksa mereka meminta bantuan dari orang lain, meskipun demikian hal ini justru menimbulkan beban tersendiri karena pasien harus tergantung pada bantuan orang lain (Dolongseda et al., 2017). Ketidakpatuhan ini berpotensi meningkat pada pasien DM tipe 2 karena proses transisi dari penggunaan obat oral hipoglikemik menjadi injeksi mandiri insulin.

Penelitian menunjukkan bahwa kepatuhan terhadap penggunaan insulin dapat meningkatkan efektivitas terapi pasien DM dan menghasilkan kontrol glikemik yang baik. Sebaliknya ketidakpatuhan meningkatkan biaya perawatan dan resiko terjadinya komplikasi antara lain retinopati, neuropati, jantung koroner, stroke dan gangguan pembuluh perifer (Srikartika et al., 2016). Oleh karena itu keberhasilan terapi insulin ditentukan oleh kepatuhan pasien dalam menggunakan insulin secara benar.

Dalam kaitannya dengan kepatuhan, perilaku memegang peranan yang sangat penting. Salah satu teori perilaku yang banyak digunakan dalam 
kasus pasien DM adalah Health Belief Model (HBM) (Karimy et al., 2016; Vazini dan Barati, 2014). Teori ini mengukur persepsi yang dirasakan oleh pasien saat menggunakan insulin berdasarkan faktor internal dari diri pasien. Faktor internal sendiri merupakan kunci penting ketika memutuskan untuk melakukan suatu tindakan.

Konsep utama HBM terdiri atas lima komponen yaitu kerentanan yang dirasakan akibat timbulnya efek samping jika tidak patuh menggunakan insulin dengan benar (Perceived Susceptibility), keparahan yang dirasakan akibat komplikasi penyakit (Perceived severity), manfaat yang dirasakan dari penggunaan insulin dengan benar (Perceived benefit), kepercayaan diri yang dirasakan saat menggunakan insulin (Perceived self-efficacy) dan hambatan yang dirasakan yang menghalangi penggunaan insulin secara benar (Perceived barier).

Insulin bukan merupakan pilihan pertama pada terapi DM tipe 2 dan hanya digunakan pada kasus ketika penggunaan Oral Anti Diabetes (OAD) tidak menunjukkan perbaikan. Dengan sistem Jaminan Kesehatan Nasional (JKN) saat ini menyebabkan pasien lebih mudah mendapatkan terapi insulin di fasilitas kesehatan tingkat lanjut seperti rumah sakit dibandingkan dengan seting fasiltas kesehatan yang lain.

Berdasarkan latar belakang tersebut perlu dilakukan penelitian lebih lanjut untuk mengukur kepatuhan pasien DM dalam menggunakan insulin yang benar dengan pendekatan teori Health
Belief Model (HBM) di seting rumah sakit.

\section{Metode Penelitian}

Penelitian ini dilakukan di suatu rumah sakit di Surabaya pada bulan April-Mei 2019. Populasi penelitian ini adalah pasien DM tipe 2 rawat jalan. Besar populasi di RS tersebut selama bulan Januari-Desember tahun 2018 adalah 524 pasien. Dengan penghitungan menggunakan rumus Slovin (Notoadmojo, 2004) didapatkan besar sampel dalam penelitian ini adalah 84 responden. Sampel dipilih menggunakan teknik purposive sampling dengan kriteria inklusi adalah pasien DM yang berusia $\geq 18$ tahun, pasien yang sudah menggunakan insulin minimal 3 bulan, pasien DM yang mendapatkan terapi insulin tunggal maupun terapi kombinasi insulin dan OAD. Kriteria eksklusi yang digunakan adalah pasien DM yang tidak bisa membaca dan menulis dan pasien DM yang hanya mendapatkan terapi OAD saja.

Instrumen yang digunakan adalah kuesioner untuk pengukuran HBM yang dimodifikasi dari kuisioner Given et al. (1983), dan kuisioner self efficacy (Ven et al., 2003). Kuisioner dalam penelitian ini menggunakan skala likert (5: sangat setuju, 4: setuju, 3: raguragu, 2: tidak setuju, 1: sangat tidak setuju). Untuk pertanyaan kepatuhan menggunakan modifikasi penelitian Bloom (1980) dengan skala likert yaitu 5: selalu, 4: sering, 3: kadang-kadang, 4: jarang, 5: tidak pernah. Analisis menggunakan uji regresi linier berganda 
dengan variabel independen adalah kerentanan yang dirasakan (perceived susceptibility), keparahan yang dirasakan (perceived severity), manfaat yang dirasakan (perceived benefit), hambatan yang dirasakan (perceived barier), kepercayaan diri yang dirasakan (perceived self-efficacy), sedangkan variabel dependen pada penelitian ini adalah kepatuhan penggunaan insulin yang benar.

\begin{abstract}
Hasil dan Pembahasan
Dari hasil karakteristik responden (Tabel 1), diketahui bahwa jumlah pasien perempuan lebih banyak dibandingkan dengan pasien laki-laki. Hal ini sesuai dengan penelitian yang dilakukan oleh Rasdianah et al. (2016) bahwa penderita DM paling banyak adalah perempuan. Hasil Riskesdas 2018 juga menyatakan bahwa prevalensi penyakit DM perempuan $(2,4 \%)$ lebih banyak dibanding laki-laki (1,7\%) (Riskesdas, 2018).
\end{abstract}

Tabel 1. Karakteristik responden

\begin{tabular}{|c|c|}
\hline Karakteristik & Jumlah (Persentase) \\
\hline \multicolumn{2}{|l|}{ Jenis Kelamin } \\
\hline Laki-laki & $41(48,8)$ \\
\hline Perempuan & $43(51,2)$ \\
\hline \multicolumn{2}{|l|}{ Usia } \\
\hline 31-40 Tahun & $5(6,0)$ \\
\hline 41-50 Tahun & $9(10,7)$ \\
\hline 51-60 Tahun & $29(34,5)$ \\
\hline$>60$ Tahun & $41(48,8)$ \\
\hline \multicolumn{2}{|l|}{ Pendidikan } \\
\hline SD & $9(10,7)$ \\
\hline SMP & $13(15,5)$ \\
\hline SMU & $36(42,9)$ \\
\hline D3 & $2(2,4)$ \\
\hline S1 & $22(26,4)$ \\
\hline s2 & $2(2,4)$ \\
\hline \multicolumn{2}{|l|}{ Pekerjaan } \\
\hline IRT & $\begin{array}{c}24(28,6) \\
1(1,2)\end{array}$ \\
\hline Pelindo & $31(36,9)$ \\
\hline Pensiunan & $2(2,4)$ \\
\hline PNS & $20(23,8)$ \\
\hline Swasta & $1(1,2)$ \\
\hline Tidak Bekerja & $1(1,2)$ \\
\hline Wiraswasta & $5(6,0)$ \\
\hline \multicolumn{2}{|l|}{ Lama Penggunaan Insulin } \\
\hline$<1$ tahun & $24(28,6)$ \\
\hline 1-5 tahun & $33(39,3)$ \\
\hline 6-10 tahun & $19(22,6)$ \\
\hline$>10$ tahun & $8(9,5)$ \\
\hline
\end{tabular}


Diketahui responden yang menggunakan insulin paling banyak berusia di atas 60 tahun sebesar $48,8 \%$. Hal ini sesuai dengan beberapa penelitian yang menjelaskan bahwa DM tipe 2 paling banyak diderita pasien di atas usia 60 tahun (Rasdianah et al., 2016; Hasbi, 2017). Karakteristik responden lainnya dapat dilihat pada Tabel 1.

Tabel 2. Hasil uji regresi linear berganda (uji F)

\begin{tabular}{ccc}
\hline Model & $\boldsymbol{F}_{\text {hitung }}$ & Sig \\
\hline Regression & 65,443 & 0,000 \\
\hline
\end{tabular}

Tabel 3. Hasil uji regresi linear berganda uji t (test significant individual parameter)

\begin{tabular}{lcc}
\hline \multicolumn{1}{c}{ Variabel Bebas } & $\mathbf{t}_{\text {hitung }}$ & Sig \\
\hline Perceived Susceptibility & 2,816 & 0,006 \\
Perceived Severity & 2,018 & 0,047 \\
Perceived Benefit & 2,262 & 0,026 \\
Perceived Barier & $-2,413$ & 0,018 \\
Perceived Self-Efficacy & 2,062 & 0,042 \\
\hline
\end{tabular}

Hasil uji regresi linier berganda Uji $F$ (Tabel 2) menunjukkan bahwa kerentanan yang dirasakan (perceived susceptibility), keparahan yang dirasakan (perceived severity), manfaat yang dirasakan (perceived benefit), hambatan yang dirasakan (perceived barier), kepercayaan diri yang dirasakan (perceived self-efficacy) berpengaruh secara simultan terhadap kepatuhan penggunaan insulin yang benar $(p=0,000)$.

Hasil uji kepada masing-masing variabel uji t (Tabel 3) menunjukkan tiap variabel berpengaruh terhadap kepatuhan pasien dalam menggunakan insulin yang benar. Kerentanan yang dirasakan (Perceived susceptibility), keparahan yang dirasakan (perceived severity), manfaat yang dirasakan (perceived benefit), dan kepercayaan diri yang dirasakan (perceived selfefficacy) memiliki hubungan positif yang signifikan terhadap kepatuhan pasien dalam menggunakan insulin yang benar (semakin tinggi semakin patuh), sedangkan hambatan yang dirasakan (perceived barrier) memiliki hubungan negatif yang signifikan (semakin rendah semakin patuh).

Kerentanan yang dirasakan (Perceived susceptibility) adalah keyakinan pada diri seseorang terkait dengan keretanan dirinya yang akan memberikan dampak pada kesehatan sehingga akan mendorong seseorang untuk perubahan pada perilaku yang lebih sehat. Hasil penelitian ini menunjukkan bahwa semakin individu merasakan kerentanan dirinya 
mengenai kesehatannya maka semakin tinggi pula tingkat kepatuhan individu dalam menggunakan insulin dan mematuhi aturan yang dianjurkan oleh tenaga kesehatan. Hasil penelitian ini sesuai dengan konsep yang dikemukakan sebelumnya bahwa seseorang akan bertindak jika merasakan dirinya rentan terhadap penyakit tersebut. Hubungan positif antara perceived susceptibility dengan kepatuhan menggunakan insulin dengan benar antara lain dipengaruhi oleh pengalaman pasien. Pengalaman memiliki peran penting yang akan membentuk persepsi, seperti kognitif, kepribadian dan budaya yang dimiliki pasien (Notoatmodjo, 2004). Kepatuhan pasien dalam medikasi penderita DM Tipe 2 akan tumbuh ketika pasien merasa bahwa penyakit yang dideritanya akan menjadi lebih parah (Ulum et al., 2015).

Keparahan yang dirasakan (Perceived severity) adalah keyakinan individu atas keparahan penyakit yang diderita. Selain itu, perceived severity juga dapat berasal dari keyakinan individu akan keparahan suatu penyakit serta dampak dari penyakit yang diderita pada kehidupannya (Buglar et al., 2010). Hasil penelitian (Tabel 3) menunjukkan bahwa ada hubungan antara keparahan yang dirasakan dengan kepatuhan pasien dalam menggunakan insulin yang benar. Hasil tersebut sesuai dengan konsep HBM yang menyatakan bahwa persepsi keparahan adalah kepercayaan individu terhadap keparahan penyakit yang dihadapi.

Manfaat yang dirasakan (perceived benefit) memiliki hubungan positif yang signifikan terhadap kepatuhan pasien dalam menggunakan insulin yang benar (Tabel 3). Manfaat yang dirasakan oleh pasien setelah melakukan suatu tindakan pencegahan melalui pengobatan maka pasien akan memiliki keyakinan jika melakukan pengobatan tersebut penyakit DM yang dideritanya akan sembuh. Dengan demikian pasien akan memiliki kepatuhan sebagai bentuk pencegahan terhadap penyakit DM yang dideritanya. Hal tersebut menunjukkan bahwa persepsi manfaat terhadap suatu pencegahan penyakit memiliki hubungan yang positif dengan kepatuhan pasien (Almira et al., 2019). Perceived benefit adalah individu yang memiliki keyakinan terhadap manfaat yang akan dirasakan apabila melakukan perilaku sehat. Manfaat yang dirasakan memiliki peran penting dalam menentukan perilaku untuk melakukan pencegahan pada suatu penyakit (Buglar et al., 2010). Semakin sadar pasien mengenai manfaat yang dirasakan dengan perilaku sehat maka akan semakin patuh pasien menggunakan insulin pada waktu, tempat, dan dosis yang benar. Maka dari itu bahwa pasien harus percaya bahwa manfaat perilaku sehat adalah penting bagi diri mereka sendiri untuk semakin sehat (Vazini dan Barati, 2014). 
Menurut Penelitian Ulum et al. (2015) menyampaikan keyakinan dan persepsi dapat dikaitkan dengan motivasi seseorang untuk melakukan suatu tindakan. Keyakinan tentang manfaat dengan mematuhi terapi sesuai yang dianjurkan tenaga kesehatan adalah menjadi hal yang penting. Hal ini sesuai dengan hasil penelitian yaitu manfaat yang dirasakan (perceived benefit) memiliki hubungan positif yang signifikan terhadap kepatuhan pasien dalam menggunakan insulin yang benar.

Hambatan yang dirasakan (perceived barier) mempunyai pengaruh negatif dan signifikan terhadap kepatuhan pasien (Tabel 3). Perceived bariers merupakan komponen yang memberikan dampak negatif pada diri individu yang akan menjadi penghalang untuk memiliki perilaku yang sehat, tujuan dari adanya teori HBM dalam menangani suatu masalah adalah hambatan yang dirasakan untuk berubah. Individu akan melakukan evaluasi terkait hambatan yang dialaminya, evaluasi tersebut dilakukan dengan cara merubah perilaku dari individu yang menjadi hambatan. Hambatan yang dirasakan memiliki peran penting dalam menentukan perubahan perilaku pada individu (Buglar et al., 2010). Pada dasarnya setiap pasien terutama pasien DM memiliki hambatan dalam mematuhi penggunaan insulin seperti halnya takut tentang jarum suntik dan tidak tahu cara penyuntikan insulin yang benar. Hambatan-hambatan tersebut menjadikan pasien tidak patuh untuk menggunakan insulin dengan benar. Semakin banyak hambatan yang dirasakan pasien dalam mematuhi penggunaan insulin, maka ketidakpatuhan pasien dalam menggunakan insulin semakin tinggi. Begitu juga sebaliknya pasien yang tidak memiliki hambatan dalam penggunaan insulin maka mempermudah dirinya untuk mematuhi aturan yang diberikan tenaga kesehatan (Vazini dan Barati, 2014).

Penelitian ini berbeda hasilnya dengan yang dilakukan oleh Hasbi (2017), yang menyatakan faktor yang mempengaruhi kepatuhan pasien DM adalah persepsi manfaat dan persepsi hambatan, sedangkan persepsi kerentanan dan persepsi keparahan menunjukkan tidak ada hubungan dengan kepatuhan pasien. Perbedaan ini disebabkan pada penelitian terdahulu kepatuhan yang dilihat adalah dalam melakukan olahraga sedangkan pada penelitian sekarang kepatuhan dalam penggunaan insulin, teori yang digunakan sama tetapi perilaku kepatuhannya yang diukur berbeda sehingga bisa menyebabkan hasilnya akan berbeda juga.

Kepercayaan diri yang dirasakan (perceived self-efficacy) mempunyai pengaruh positif dan signifikan terhadap kepatuhan pasien (Tabel 3). Self-efficacy merupakan keyakinan yang dimiliki oleh individu yang mampu untuk menyuntikkan insulin yang benar. Apabila individu memiliki kepercayaan pada perubahan pada perilaku, maka 
hal tersebut sebagai manfaat yang dirasakan. Adanya kepercayaan pada perilaku baru yang berasal dari manfaat yang dirasakan akan meningkatkan kepatuhan pasien (Buglar et al., 2010). Keyakinan seseorang terhadap kesembuhan penyakit yang diderita akan memiliki motivasi untuk melakukan suatu tindakan. Keyakinan pasien terhadap dampak yang diperoleh dengan mematuhi terapi medikasi sesuai dengan anjuran medis yang menunjukkan positif. Hal tersebut membuktikan bahwa pasien penderita DM memiliki meyakini terdapat manfaat yang diperoleh kalau patuh dalam melakukan pengobatan dengan terapi insulin (Ulum et al., 2015).

Penelitian yang dilakukan Prasetyowati et al. (2018) menunjukkan bahwa ada efek positif dari self efficacy pada perawatan pencegahan pada pasien dengan DM tipe 2. Pasien dengan self efficacy yang tinggi akan meningkatkan perawatan diri DM 2, dimana seseorang yang memiliki self efficacy yang baik akan lebih patuh pada perilaku preventif untuk melakukan suatu pencegahan. Pasien DM dengan perubahan perilaku diperlukan untuk mencapai tujuan manajemen DM seperti kadar gula dalam batas normal. Self-efficacy adalah keyakinan pasien dalam bertindak dan berperilaku yang sesuai dengan harapan pasien dan tenaga kesehatan. Selfefficacy dapat mempengaruhi kepatuhan melalui pemikiran, motivasi diri, dan tindakan. Hasil berbeda juga ditunjukkan oleh penelitian Ulum et al. (2015) yang menyatakan bahwa perceived severity, perceived benefit, dan self-efficacy memiliki hubungan signifikan dengan kepatuhan medikasi penderita DM tipe 2, sedangkan perceived susceptibility dan perceived barrier tidak memiliki hubungan secara signifikan dengan kepatuhan medikasi penderita DM Tipe 2.

Tabel 4. Hasil koefisien regresi (B)

\begin{tabular}{lc}
\hline & Koefisien Regresi (B) \\
\hline Constant & 1,817 \\
Perceived Susceptibility & 0,261 \\
Perceived Severity & 0,162 \\
Perceived Benefit & 0,112 \\
Perceived Barier & 0,214 \\
Perceived Self-Efficacy & 0,137 \\
\hline
\end{tabular}

Berdasarkan Tabel 4 diketahui bahwa kerentanan yang dirasakan (perceived susceptibility) mempunyai nilai paling besar yaitu 0,261 dibandingkan variabel lainnya. Oleh karena itu persepsi kerentanan memiliki pengaruh yang paling besar terhadap kepatuhan pasien dalam menggunakan 
insulin. Hal ini berarti pasien mempunyai keyakinan kerentanan yang besar terhadap resiko efek samping apabila tidak patuh dalam menggunakan insulin yang benar. Hasil penelitian ini berbeda dengan penelitian Karimy et al. (2016) dan Dehganitafti et al. (2015) yang menyatakan self-efficacy adalah faktor yang paling kuat untuk menentukan kepatuhan pasien DM. Hasil berbeda juga ditunjukkan pada penelitian Ulum et al. (2015) yang menunjukkan faktor yang paling besar mempengaruhi kepatuhan medikasi adalah faktor keparahan.

Hasil dari penelitian ini agar RS mengetahui faktor yang mempengaruhi kepatuhan pasien DM dalam menggunakan insulin yang benar, sehingga dapat menjadi bahan evaluasi untuk terapi insulin selanjutnya. Kelebihan dalam penelitian ini terkait faktor yang mempengaruhi kepatuhan pasien DM dalam penggunaan insulin belum pernah dilakukan penelitian di rumah sakit, kekurangan adalah dalam penelitian ini tidak melihat bagaimana pengaruh karakteristik responden terhadap kepatuhan pasien dalam menggunakan insulin.

Yang perlu dilakukan oleh pihak RS adalah harus meningkatkan pemahaman pasien tentang efek samping penggunaan insulin, untuk mempertahankan dan meningkatkan perilaku kepatuhan pasien DM dalam menggunakan insulin maka perlu membuat kelompok pertemuan secara rutin antara pasien DM yang menggunakan insulin dengan dokter dan apoteker agar bisa diskusi dan konsultasi dalam hal pemakaian insulin dan permasalahan yang sering terjadi pada pasien. Selain itu petugas kesehatan bisa mengadakan edukasi pada pasien DM untuk melakukan penyuluhan secara berkala pada pasien baik di rumah sakit maupun dengan kunjungan rumah agar dapat meningkatkan kepatuhan pasien pada penggunaan insulin (Almira et al., 2019).

\section{Simpulan}

Perceived succeptibility, perceived severity, perceived benefit, perceived self-efficacy memiliki pengaruh yang positif sedangkan perceived barrier memiliki pengaruh yang negatif terhadap kepatuhan pasien dalam menggunakan insulin dengan benar. Pengaruh ini dapat berlaku secara simultan maupun untuk masingmasing variabel. Perlu dilakukan upaya terstruktur dari pihak RS dan berkelanjutan untuk meningkatkan komponen 1-4 dan menurunkan komponen 5 .

\section{Daftar Pustaka}

Alfian, R. 2016. Hubungan antara pengetahuan dengan kepatuhan tentang penggunaan insulin pada pasien diabetes mellitus di Poliklinik Penyakit Dalam RSUD. Dr. H. Moch. Ansari Saleh Banjarmasin. Jurnal Ilmiah Ibnu Sina,1(1):918. 
Aini, N., Fatmaningrum, W., Yusuf, A. 2011. Upaya meningkatkan perilaku pasien dalam tatalaksana diabetes mellitus dengan pendekatan teori model behavioral system Dorothy $\mathrm{E}$. Johnson. Jurnal Ners, 6(1):1-10.

Buglar, M.E., White, K.M., Robinson, N.G. 2010. The role of selfefficacy in dental patients' brushing and flossing: test an extended health belief model. Patient Education And Counseling, 78(2):269-272.

Almira, N., Arifin, S., Rosida, L. 2019. Faktor-faktor yang berhubungan dengan perilaku kepatuhan minum obat anti diabetes pada penderita diabetes melitus tipe 2 di Puskesmas Teluk Dalam Banjarmasin. Homeostasis, 2(1):9-12.

Dolongseda, F.V., Masi, G.N., Bataha, Y.B. 2017. Hubungan aktivitas fisik dan pola makan dengan kadar gula darah pada pasien diabetes melitus tipe II di Poli Penyakit Dalam Rumah Sakit Pancaran Kasih GMIM Manado. e-journal Keperawatan, 5(1):18.

Dehganitafti, A., Mazloomy, M.S.S., Morowatisharifabad, M.A., Afkhami, A.M., Rezaeipandari, H., Lotfi, M.H.I. 2015. Determinants of self-care in diabetic patients based on health belief model. Global Journal of Health Science, 7(5):33-42.
Given, C.W., Given, B.A., Gallin, R.S., Condon, J.W. 1983. Development of scale to measure beliefs of diabetic patients. Research in Nursing \& Health, 6:127-141.

Glanz, K., Rimer, B.K., Viswanath, K. 2008. Health Behavior and Health Education, Theory, Research, and Practice. $4^{\text {th }}$ Ed. San Francisco: Jossey-Bass A Willey Imprint.

Ghozali, I. 2016. Aplikasi Analisis Multivariate dengan program IBM SPSS 23. Edisi 8 Cetakan VIII. Semarang: Badan Penerbit Universitas Diponegoro.

Hasbi, M. 2017. Analisis faktor yang mempengaruhi kepatuhan penderita diabetes melitus dalam melakukan olahraga di wilayah kerja Puskesmas Praya Lombok Tengah. Jurnal Kesehatan Prima, 11(1):76-82.

Karimy, M., Araban, M., Abedi, A. 2016. Determinants of adherence to self-care behavior among women with type 2 diabetes: an explanation based on health belief model. Medical Journal of the Islamic Republic of Iran, 30:1-8.

Notoatmodjo, S. 2004. Metodologi Penelitian Kesehatan. Jakarta: PT. Rineka Cipta.

Ven, N.C.W., Weinger, K., Yi, J., Pouwer, F., Ader, H., Ploeg, H.M., Snoek, F.J. 2003. The confidence in diabetes self-care scale. Diabetes Care, 26(3):713-718. 
Perkeni. 2015. Konsensus Pengelolaan dan Pencegahan Diabetes Mellitus Tipe 2 di Indonesia. Jakarta: Perkeni.

Prasetyowati, U., Tamtoto, D., Murti, B. 2018. Path analysis: factors associated with self preventive care among patients with type 2 diabetes mellitus in Surakarta. Journal of Health Promotion and Behavior, 3(2):86-93.

Rasdianah, N., Martodiharjo, S., Andayani, T.M. Hakim, L. 2016. Gambaran kepatuhan pengobatan pasien diabetes melitus tipe 2 di Puskesmas Daerah Istimewa Yogyakarta. Jurnal Farmasi Klinik Indonesia, 5(4):249-257.

Riset Kesehatan Dasar (Riskesdas). 2018. Riskesdas. Jakarta: Badan Penelitian dan Pengembangan Kesehatan Kementerian RI.

Rubin, R.R., Mark, P., Davida, F.K., Luther, B.T. 2009. Barriers to insulin injection therapy: patient and health care provider perspective. The Diabetes Educator, 35:10141036.
Shabibi, P., Zavarech, M.S.A., Sayehmiri, K., Qorbani, M., Safari, O., Rastearimehr, Mansourian, M. 2017. Effect of educational intervention based on the health belief model on promoting self-care behaviors of type-2 diabetes patients. Electronic Physician, 9(12):5960-5968.

Srikartika, V.M., Cahya, A.D., Hardiati, R.S.W. 2016. Analisis faktor yang mempengaruhi kepatuhan penggunaan obat pasien diabetes melitus tipe 2. Jurnal Manajemen dan Pelayanan Farmasi, 6(3):205-212.

Ulum, Z., Kusnanto, Widyawati, I.Y. 2015. Kepatuhan medikasi penderita diabetes mellitus tipe 2 berdasarkan teori health belief model (HBM) di wilayah kerja Puskesmas Mulyorejo Surabaya. Jurnal Keperawatan Airlangga, 4(1):1-11

Vazini, H. dan Barati, M. 2014. The health belief model and selfcare behaviors among type 2 diabetic patients. Iranian Journal of Diabetes and Obesity, 6(3):107-113. 